\title{
DÜBLIN
}

Technological University Dublin

ARROW@TU Dublin

Articles

School of Surveying and Construction

Management

2020

\section{Thermal analysis and post construction verification}

\author{
Cormac Flood \\ Technological University Dublin, cormac.flood1@gmail.com \\ Lloyd Scott \\ Technological University Dublin, Iloyd.scott@tudublin.ie
}

Follow this and additional works at: https://arrow.tudublin.ie/beschrecart

Part of the Construction Engineering and Management Commons, Environmental Engineering

Commons, and the Structural Engineering Commons

\section{Recommended Citation}

Flood, C. and Scott, L. (2020), "Thermal analysis and post construction verification", International Journal of Building Pathology and Adaptation, Vol. 38 No. 1, pp. 51-67. https://doi.org/10.1108/

IJBPA-12-2018-0098

This Article is brought to you for free and open access by the School of Surveying and Construction Management at ARROW@TU Dublin. It has been accepted for inclusion in Articles by an authorized administrator of ARROW@TU Dublin. For more information, please contact arrow.admin@tudublin.ie, aisling.coyne@tudublin.ie, gerard.connolly@tudublin.ie.

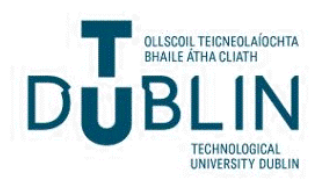




\title{
Thermal analysis and post construction verification
}

\author{
Cormac Flood and Lloyd Scott
of Surveying and Construction Management, \\ Cormac Flood and Lloyd Scott
School of Surveying and Construction Management,
Dublin Institute of Technology, Dublin, Ireland \\ Cormac Flood and Lloyd Scott
Dublin Institute of Technology, Dublin, Ireland
}

Abstract

Purpose - The residential sector in Ireland accounted for 25 per cent of energy related CO2 emissions in 2016 through burning fossil fuels, a major contributor to climate change. In support of Ireland's CO2 reduction targets, the existing housing stock could contribute greatly to the reduction of space-heating energy demand through retrofit. Approximately 50 per cent of Ireland's $2 \mathrm{~m}$ dwellings pre-date building regulations and are predominantly of cavity and solid wall construction, the performance of which has not been extensively investigated at present. Although commitment to thermal upgrade/retrofit of existing buildings may increase under future government policies, the poor characterisation of actual thermal performance of external walls may hinder the realisation of these targets. Thermal transmittance ( $U$-values) of exterior walls represents a source of uncertainty when estimating the energy performance of dwellings. It has been noted in research that the standard calculation methodology for thermal transmittance should be improved. Implementing current $U$-value calculation methods may result in misguided retrofit strategies due to the considerable discrepancies between in situ measurements and calculated wall $U$-values as documented in the case studies carried out in this research. If the method of hygrothermal analysis were to be employed as a replacement for the current standard calculation, it could have significant implications for policy and retrofit decision making. The paper aims to discuss this issue.

Design/methodology/approach - This research project analysed a case study situated in Dublin, Ireland. The case studies offer an account of the in situ thermal transmittance of exterior walls and link these to hygrothermally simulated comparisons along with more traditional design $U$-values.

Findings - The findings of this research identify discrepancies between in situ and design $U$-values, using measurement, hygrothermal simulation and standard method $U$-value calculations. The outcomes of the research serve as an introduction to issues emanating from a larger research project in order to encourage researchers to understand and further explore the topic.

Originality/value - It has previously been highlighted that moisture content is linked to the increase in thermal conductivity of building materials, thus reducing the thermal effectiveness and increasing the elemental $U$-value. Therefore, it is vital to implement reliable prediction tools to assess potential thermal performance values. This paper presents the findings of a critical instance case study in Dublin, Ireland in which an existing west facing external wall in a semi-detached dwelling was analysed, simulated and measured to verify the elemental wall assembly and quantify thermal transmittance ( $U$-value) incorporating the major criteria required for building performance simulation.

Keywords Climate change, Retrofit, Hygrothermal analysis, $U$-values

Paper type Case study

\section{Introduction}

Design and assessment are used all around us, in every part of our lives. We make judgements, assess the purpose, intent and outcome depending on the context. The importance of accurate design and assessment of the $U$-value does not solely relate to building compliance regarding minimum heat loss requirements. Rather, in construction, it has particular and much broader functions, as elaborated upon later in the paper. It certainly estimates the heat loss through a building fabric (the thermal performance of the building), but it has a role to play in contributing to thermal comfort, quality of life, fuel resources, energy management and, most importantly, sustainability. This paper reports the overall findings from a larger research enquiry, an explorative study into $U$-value design and assessment practices in the built environment in Ireland. The main goal was to understand the full application of the $U$-value and how this can be linked to the complex assessment of the building fabric, post construction, with a focus on walls in existing dwellings. This research falls within the broad domain of built environment,

Received 4 December 2018

Revised 28 March 2019 8 May 2019

Accepted 19 May 2019
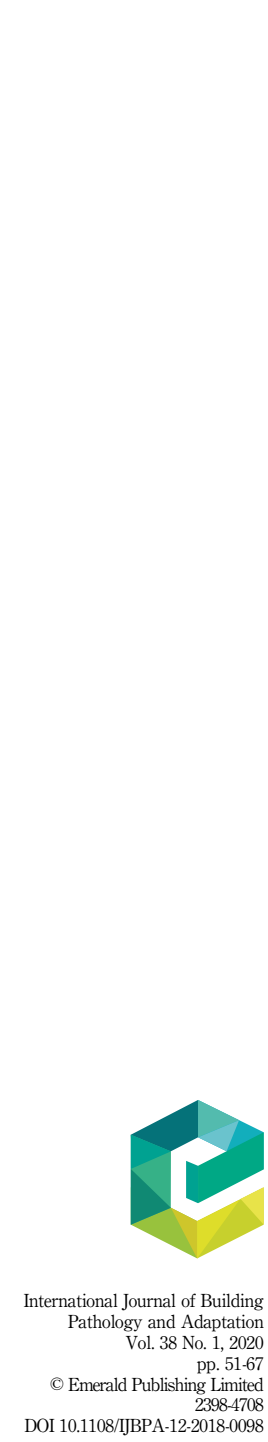
IJBPA

38,1

construction research, ideological, political and sociological considerations, where each has some level of impact on the topic.

As technology advances, so does construction knowledge, understanding, expertise and design. Within the context of new build, this has allowed for increased accuracy of construction detailing which ensures energy efficiency targets are reached through optimal building performance. In contrast to this, improvements in thermal performance of the existing building stock are limited to retrofit works which contribute to similar building performance levels. As such, technology must be adapted to facilitate understanding and development of retrofit solutions for application to existing building elements while considering the potential consequences of each.

It has previously been highlighted that moisture content is linked to the increase in thermal conductivity of building materials, thus reducing the thermal effectiveness and increasing the elemental $U$-value (Flood et al., 2016a, b; Latif et al., 2016; Abdou and Budaiwi, 2013; Gomes et al., 2017). Therefore, it is vital to implement reliable prediction tools to assess potential thermal performance values. What is presented here are the findings of a critical instance case study in Dublin, Ireland in which an existing west facing external wall in a semi-detached dwelling was analysed, simulated and measured to verify the elemental wall assembly and quantify thermal transmittance ( $U$-value) incorporating the major criteria required for building performance simulation (BPS). The results of standard calculated $U$-values are presented alongside comparable non-destructive, measured in situ $U$-values, while both are compared to results of simulated moisture dependent $U$-values. A process of data collection was adhered to as follows:

(1) borescope enquiry to verify elemental assembly of wall;

(2) calculation of $U$-values in accordance with ISO 6946 + the Irish Technical Guidance Document Part L;

(3) infrared thermographic survey in accordance with ISO 6781 to identify irregularities;

(4) measurement of $U$-values in situ in accordance with ISO 9869; and

(5) simulation of moisture dependant $U$-values using hygrothermal assessment software (WUFI) in accordance with EN 15026 and ASHRAE 160P.

The borescope investigation is a verification method which enables clarification of the existing wall assembly. It was performed on the building fabric both internally and externally to clearly identify the structure, materials and the extent/presence of insulation. This facilitated the calculation of $U$-values of an accurate representation of the existing wall assembly.

The objective of thermographic imaging was to highlight existing thermal bridges, cracks or similar sources of irregularities in surface temperatures contra venous to the typical thermal performance of the wall. As a result, a suitable location was selected for the heat flux meter (HFM) and thermocouples intended for in situ $U$-value measurement.

In situ $U$-values have been measured by using the HFM method performed in agreement with ISO 9869. Accordingly, measurements have been carried out for 30 days with an acquisition time lapse of 5 min during the winter season. The measured $U$-values are presented alongside the calculated and simulated $U$-values of matching environmental conditions and construction type to facilitate comparison.

\section{Theory}

\subsection{U-values and the performance gap}

As building design has developed, energy loss figures have become more important to accurately define, a key reason being the implementation of these figures to derive greenhouse gas reduction targets (SEAI, 2015). The $U$-value from building energy rating reports is one of 
these figures used. However, significant discrepancies have been purported between design $U$-value targets in buildings compared to actual operating performance in situ. This "performance gap" is associated with a number of contributing factors in the design and construction of the building envelope (Gorse, 2015; Ahn et al., 2017; Marshall et al., 2017; Kampelis et al., 2017). Most buildings have a performance gap, comprising energy consumption, greenhouse gas emissions and occupant comfort. The Green Construction Board Buildings Working Group found that UK non-domestic buildings typically use around 200 per cent more energy than predicted (Board, 2013), while inaccurate BPS has been cited as one cause for this performance gap within buildings (Knapton, 2017). The figure for the $U$-value, for instance, is strongly correlated to the material water content (Litti et al., 2013; Doran et al., 2014). This correlation between water content and heat flow necessitates the understanding of the long-term performance through reliable prediction tools to assess thermal performance values.

Buildings are continually subject to fluctuating internal and external climate conditions such as temperature, moisture, solar radiation and wind. WDR has an effect on the hygrothermal changes of materials depending on the climate and orientation (De Mets et al., 2017). These variations represent potential key factors that affect and define the actual physical thermal performance and sustainability of the building envelope (Litti et al., 2013; Doran et al., 2014). As such, all techniques for the simulation of hygrothermal behaviour of building components are issues of great interest in building design, where the goal of accurate design is vital. The result of such an approach to design should be an envelope that anticipates internal and external environmental conditions, allowing the building to perform to its optimum.

Early research published from 1998 has investigated the requisite for in situ measurement to verify calculated $U$-values used commonly throughout the construction industry. Haralambopoulos and Paparsenos (1998) suggest that in situ measurement can be reliable as a non-destructive test of the thermal characteristics of new or old buildings. Doran (2000) proposed the international need for a better understanding of air and moisture movement within opaque building elements, while others (Baker, 2008; Currie et al., 2013) outlined the basic technique required to implement in situ $U$-value measurement. Since then, various publications have presented numerous wall assembly analysis, contending that measurements generally highlight a vast performance gap between design values and in situ results (Doran and Carr, 2008; Peng and Wu, 2008; Rye, 2010; Byrne et al., 2013; Asdrubali et al., 2014; Evangelisti et al., 2015). Baker (2011) and Rye and Scott (2012) conveyed that $U$-value calculations generally overestimate in situ thermal performance in traditional buildings. In other words, uninsulated traditional buildings actually perform better than expected from design values. In contrast to this, Hulme and Doran (2015) argued that depending on the wall structure and insulation levels, the reliance on in situ values varied considerably from overestimation to underestimation of design $U$-value. Rhee-Duverne and Baker (2013) then went on to claim that if the thermal conductivity values are known, calculations using software programs can be in reasonable agreement with measured $U$-values, suggesting that much of the discrepancies related to calculated $U$-values is linked with the quality of the data used.

This study employs hygrothermal simulation as a method to embrace the major criteria required to carry out a true evaluation of the $U$-value. Hygrothermal simulation is a method of BPS which facilitates analysis of moisture levels within building elements based on combined heat, air and moisture movement emanating from internal and environmental conditions. This data can then be applied monthly averaged $U$-values simulated over a number of years with more accurate $U$-values incorporating in situ site conditions. The results highlight a number of issues pertaining to BPS of existing buildings, pre- and post-retrofit:

- Uncertainties pertaining to the investigation and documentation of existing building element assemblies are evident. This applies to all orientations of a building and is connected to a number of issues including the knowledge provided by building owners. 
IJBPA

38,1

- Moisture levels within building elements are substantial and increase over time.

- The effect of moisture on the $U$-value of building elements is significant and increases over time.

Quite simply, reliable simulation of existing wall assemblies pre- and post-retrofit requires accuracy. This refers to both the documentation of the existing wall assembly, but also the conditions of the structure, intermediate retrofit solutions already applied and age bands for construction and retrofit upgrade works. Obviously, there will be some ambiguity regarding the properties of building materials in situ due to varying internal and external climate conditions for different periods of time across diverse climates. Additionally, building materials experience changes in thermal effectiveness due to moisture content over time while internal and external conditions cannot be predicted with absolute certainty. Therefore, it should be noted that no simulated value will truly be an exact representation of in situ performance. Nevertheless, hygrothermal simulation is a step in the right direction for accurate simulation of the $U$-value incorporating major criteria required as alluded to on previous research by the authors.

\subsection{Previous research involving hygrothermal simulation and energy measurement}

Hygrothermal simulation is designed to provide realistic heat and moisture conditions and is validated as doing so. WUFI software requires standard material properties and moisture storage and liquid transport functions. For boundary conditions, measured outdoor climates - including driving rain and solar radiation - are used.

Early research published in 2009 has investigated the requisite for hygrothermal simulation to verify expected moisture levels in external masonry walls. Little $(2009,2010)$ suggested a requirement for the need to understand better the effects which insulating building elements can create. He goes on to contend that current guidance on refurbishment is inadequate, lacking further investigation into the fundamental understanding of building performance. Künzel et al. (2005) documented the process of using hygrothermal simulation to verify simulated internal relative humidity and temperature against measured values, while Zirkelbach et al. (2017) backed up claims that hygrothermal simulations are suitable for moisture and energy performance simulations, which have been shown to correlate with in situ measurements.

With all the above considered, hygrothermal simulation to establish the $U$-value is certainly a reasonable and practical option to establish actual thermal performance of external walls. To do this, a link between hygrothermal simulations and in situ $U$-value measurements was made. The in situ measurement process begins with thermographic surveying, particularly relevant as this research is focused on existing and retrofit dwellings.

\section{Materials and methods methodology}

The methodology used in this phase of the research is modelled around multi-methodological design, incorporating some qualitative research to allow a fuller piece of research (Creswell, 2009). Data collection and analysis through past and present research by others (along with policy design standards, recorded climate data, housing figures, common external wall constructions, standard design calculation methodologies and non-standard design calculation methodologies) corresponds well with and suits the theory of a quantitative methodological approach (Corbetta, 2003; Maxwell, 2013). The research is structured, performing a series of calculations and recording performance data to produce results which clarify the question. A qualitative approach was used to develop an understanding of the problem and improve methods for the quantitative element of research. 
The case study is a 1980s, two storey semi-detached dwelling in Dublin, Ireland with three exposed facades (East, South and West). The West façade was selected for this study due to previous research by the author indicating that further investigation of an extended analysis duration would be beneficial to those results.

Measurements of the wall depth and data provided by the residents had specified that the wall assembly was plasterboard on $40 \mathrm{~mm}$ Polyisocyuranate internal insulation on $20 \mathrm{~mm}$ sand/cement plaster on $100 \mathrm{~mm}$ block, empty cavity and $100 \mathrm{~mm}$ block with $15 \mathrm{~mm}$ sand/cement render. An investigatory survey was carried out to verify and record the wall assembly. The existing wall was inspected using an $8 \mathrm{~mm}$ Wi-Fi enabled endoscope through a $10 \mathrm{~mm}$ externally drilled hole recorded wirelessly via smart phone. A live video feed was transmitted to the mobile phone and images were captured as records for the study. In addition to the external survey, the internal layers were surveyed by removing a skirting board. The survey identified the wall as plasterboard and $15 \mathrm{~mm}$ expanded polystyrene (EPS) internal insulation on $20 \mathrm{~mm}$ sand/cement plaster on a single layer of hollow block with a double layer of $15 \mathrm{~mm}$ external render (Refer to Figure 1 and Plates 1-8).

The thermographic survey of this case study was undertaken on the 11 December 2016, which commenced at 23:50 h. The environmental data recorded at the time of the survey and the meteorological data are set out in Table I.

Figures 2 and 3 are the photograph and thermogram, respectively, of this case study. The photograph in Figure 2 was taken during the day of the thermographic survey and it indicates the section of wall identified to be analysed, simulated, and measured using hygrothermal analysis and in situ $U$-value measurement. The thermogram in Figure 3 appears to confirm that the wall surface temperature is evenly spread, validated through a consistent orange/blue across the wall surface, thus thermal irregularities are not encountered. The warmer orange/yellow line identified in the thermogram is an exposed heating pipe feeding the radiator for that room, which is $600 \mathrm{~mm}$ away from the sensors, and is not considered to pose any considerable risk to results (Plates 9-11).

Figure 2 shows the basic image of an internal wall surface, while Figure 3 is the corresponding thermographic image which confirms no thermal irregularities which may have distorted results. Thermal paste/grease was applied on the wall side of the HFM to ensure full connection to the wall surface. The HFM was then fixed to the wall surface using a masking tape to the edges away from the meter within the plate, to eliminate any effect to the heat flux readings.

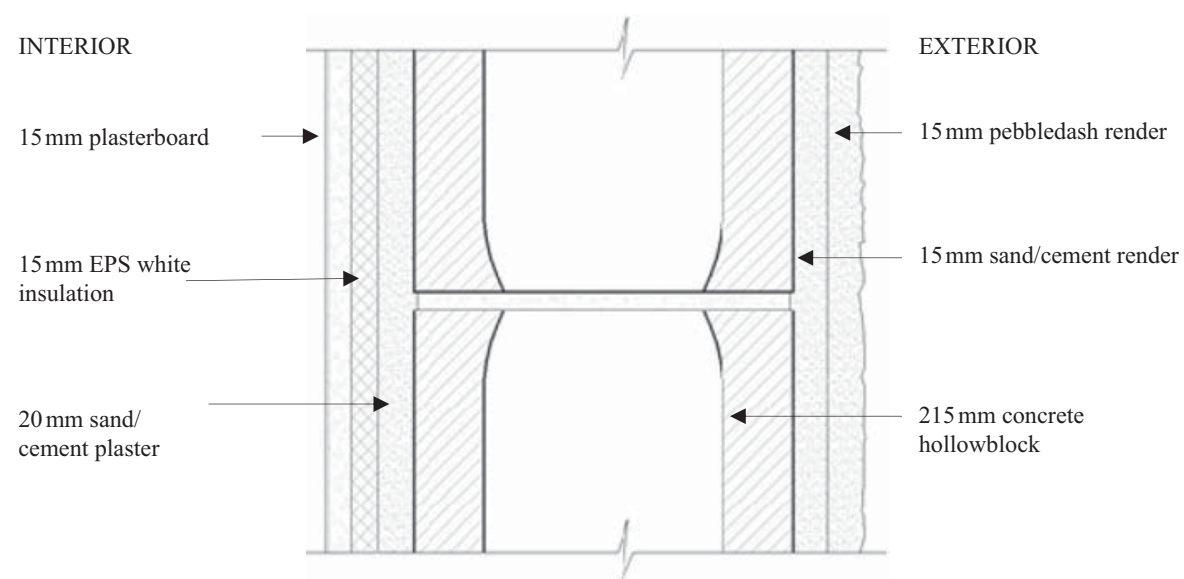

Figure 1 .

Wall detail of case study 


\section{IJBPA 38,1}

Plate 1.

Case study image

Plate 2.

Wi-Fi endoscope
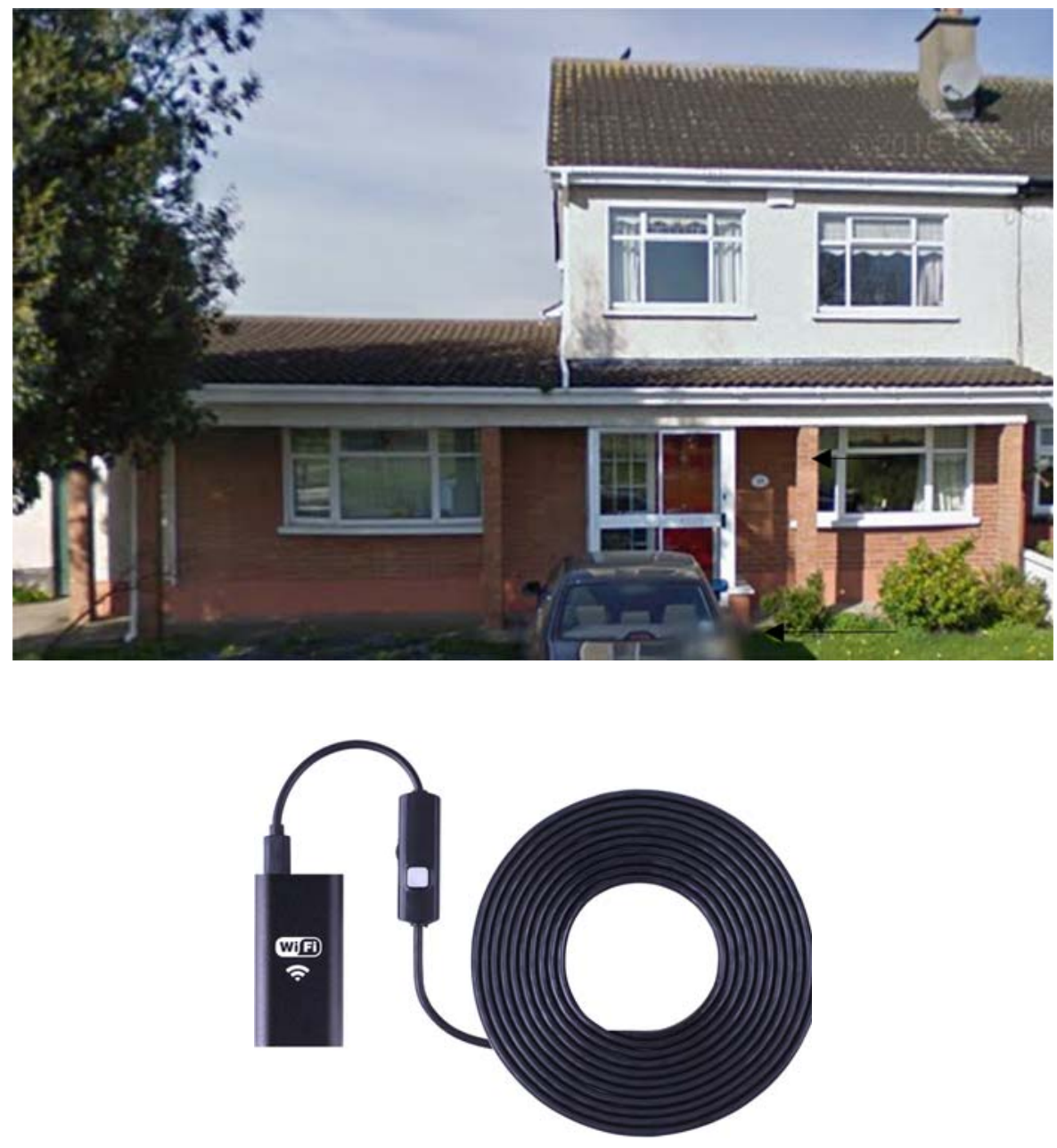

The probes used for monitoring internal temperatures were usually located approximately $50 \mathrm{~mm}$ from the internal wall surface and were located at the same height as the adjacent HFM, and positioned to face the room (i.e. to receive a similar radiant temperature to that of the room interior). For the external air temperature, the probes were positioned (housed within a hanging tube shielding to reduce the effect of direct solar radiation) about $50 \mathrm{~mm}$ from the external wall surface, fixed to the wall surface using $9 \mathrm{~mm}$ round cable clips to provide anchoring. The elemental $U$-value was determined by logging differential voltage from HFM sensor and temperature from calibrated T-type thermocouples (resistance) continuously over the 30-day study.

\section{Findings}

As a starting point, traditional $U$-values were set as a benchmark. The existing wall assembly was then modelled in WUFI and simulated to determine discrepancies between standard and simulated values incorporating major criteria required for accurate BPS. 


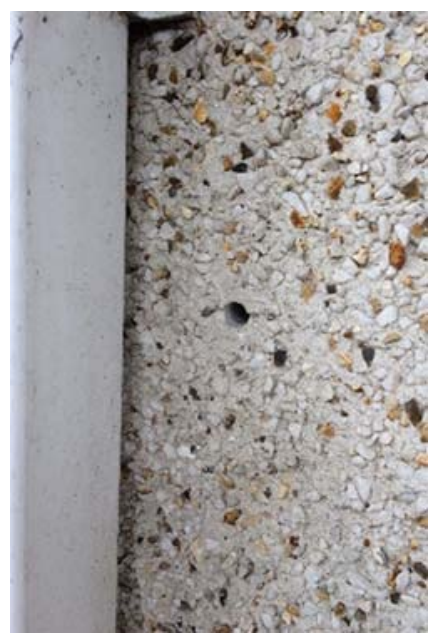

Thermal analysis

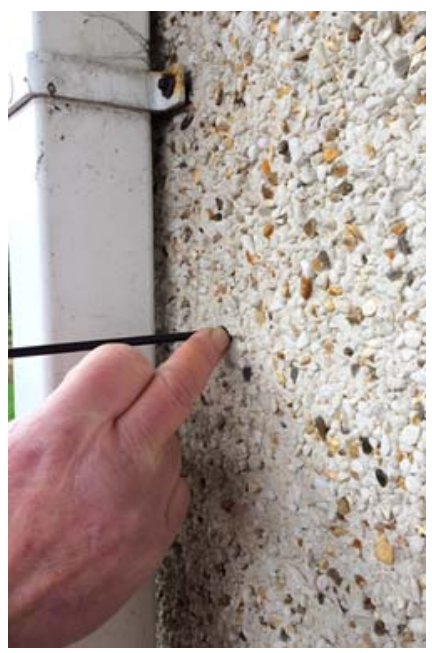

Plate 3.

$10 \mathrm{~mm}$ drilled hole

Plate 4.

Endoscope inserted

The results of the simulation were then compared to in situ measured $U$-values of the same wall assembly to ensure simulated results were representative of true values.

\subsection{Challenging the norm}

The existing wall assembly was modelled in WUFI and hygrothermally simulated to confirm any discrepancies between calculated, measured and simulated values incorporating major criteria required for accurate BPS as outlined in Chapter 5. The hollow block was modelled as solid, in line with previous published research (Little, 2009). A number of key observations were established in this case study using hygrothermal analysis and in situ measurement, as a direct result of testing carried out in previous research papers (Flood et al., 2016a, b, 2017). 


\section{IJBPA}

38,1

\section{8}

\section{Plate 5.}

Endoscope image inside wall cavity
Plate 6.

Endoscope image inside internal insulation
Plate 7.

Endoscope image inside internal insulation
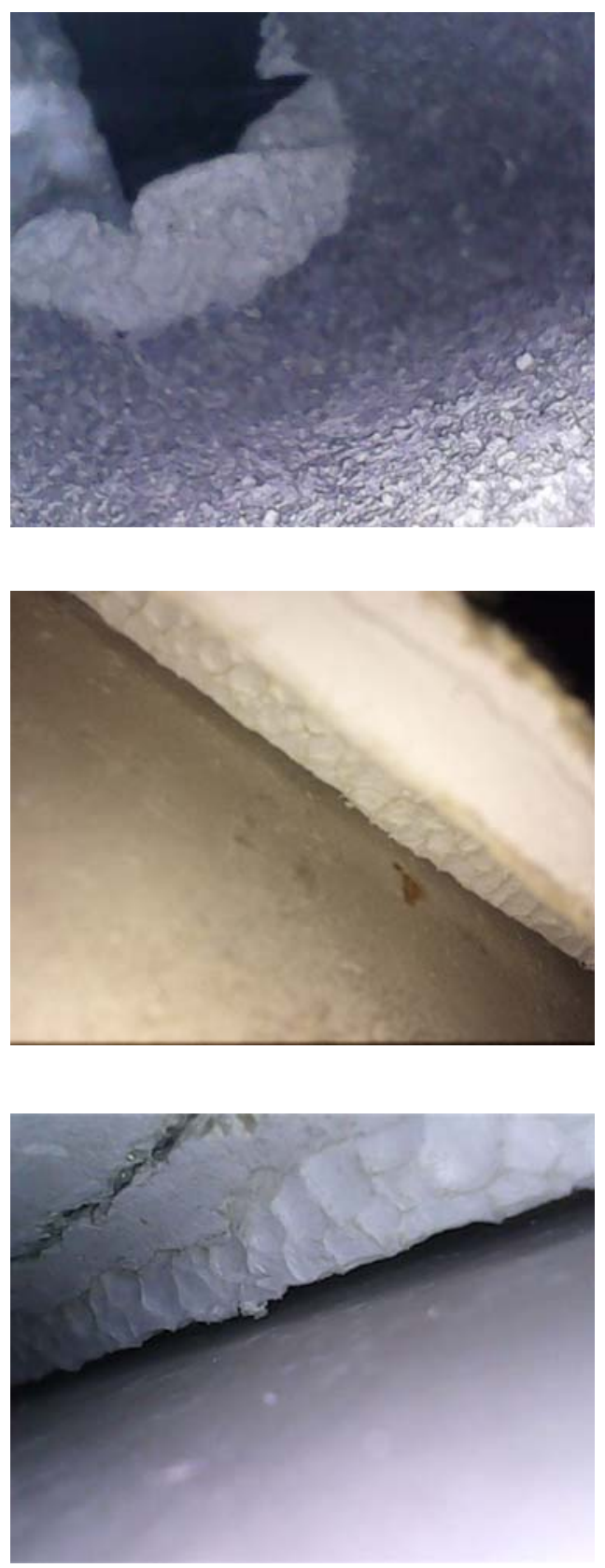

First, through simulation of the wall assembly in this case study and a review of previous simulations, it is noted that the wall assembly displays increasing moisture loading even after the three-year period previously simulated. For this study, the simulation period was increased significantly to establish the point at which moisture stabilisation is encountered. 


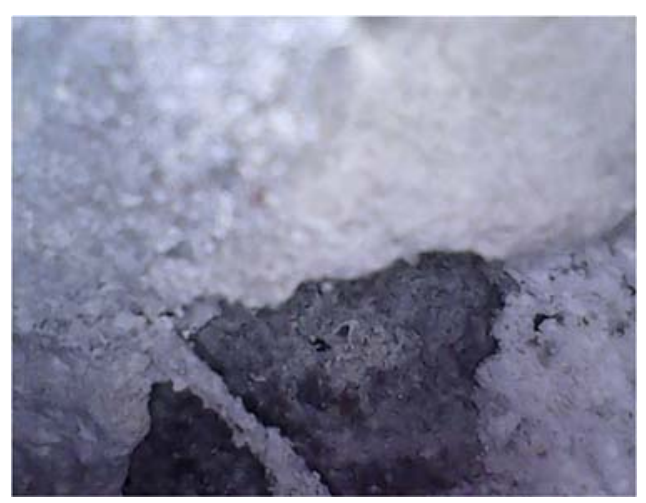

Thermal analysis

Plate 8.

Endoscope image behind internal insulation

Location

Orientation

Date

Time

External temperature

Internal temperature

Infrared imager used
Tallaght, Case Study 5

West façade

11 December 2016

23:50

$9^{\circ} \mathrm{C}$

$21^{\circ} \mathrm{C}$

FLIR P620
Table I.

Recorded

environmental data prior to survey

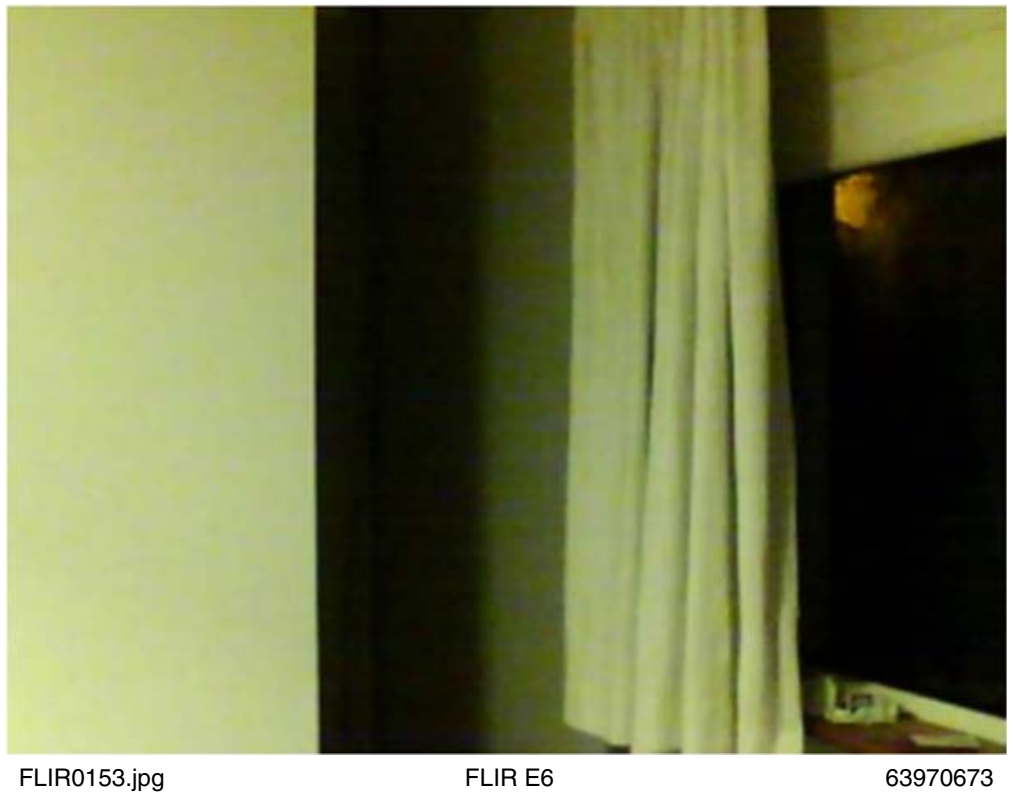

Figure 2.

Image of internal wall surface 
IJBPA

38,1

60

Figure 3.

Thermographic image

of internal

wall surface

Plate 9.

HFM and internal thermocouple fixed

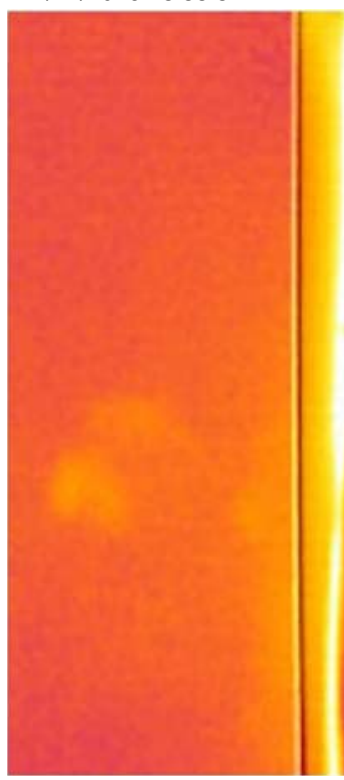

FLIR0153.jpg

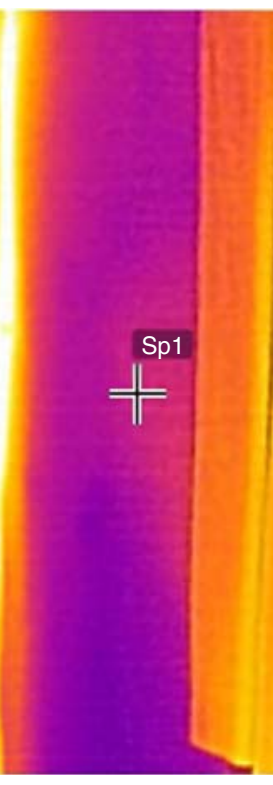

FLIR E6
${ }^{\circ} \mathrm{C}$

\section{4}

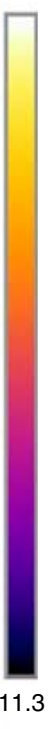

63970673

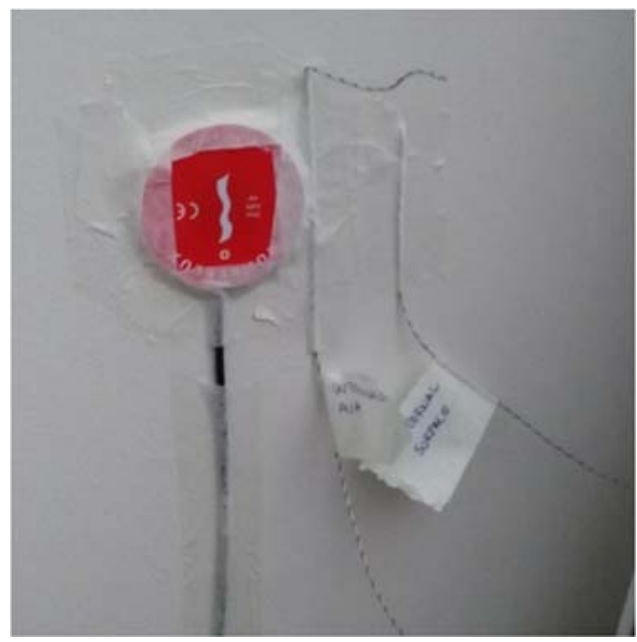

Accordingly, a 10-year simulation period was concluded as the period required for significant oscillations in moisture content profiles to stabilise, as per Figure 4 below. This moisture content, as previously established, has a direct correlation with $U$-value performance of wall assemblies on a varying scale.

Is it discernible that the critical phase of simulation is years 1 to 5 , which would typically be referred to as the "drying out" period for a new build? Council (2016) make reference to 


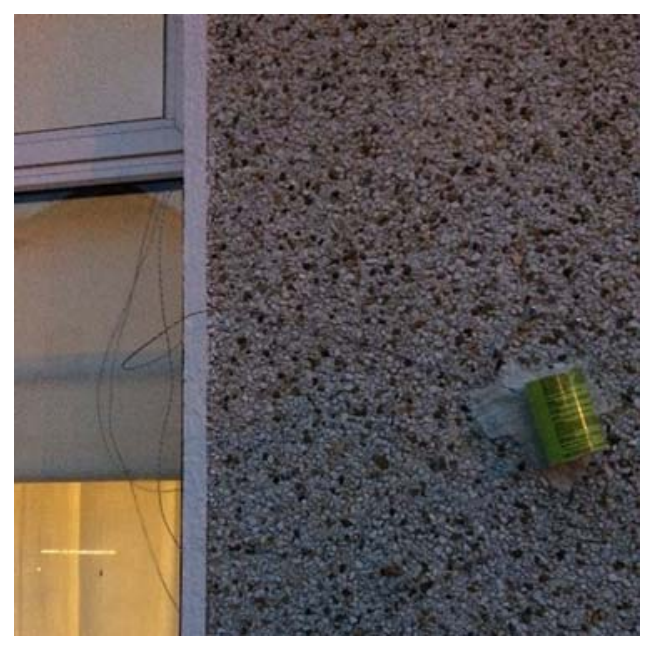

Thermal analysis

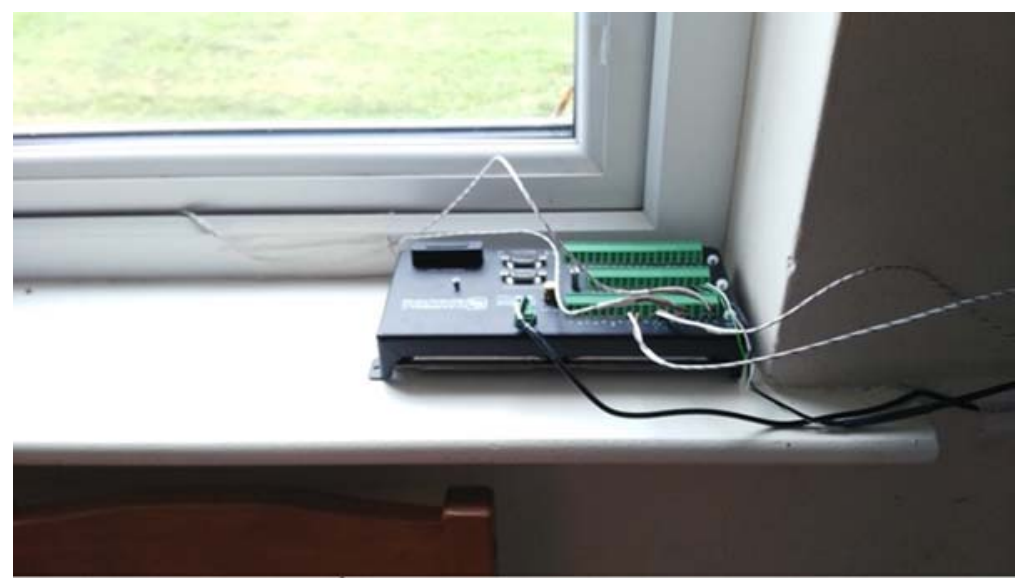

Plate 11.

Datalogger rested on window sill for duration of study

how "the building dries out" and "when the building itself has finished drying out", which would suggest that the building dries out completely. What should be noted here is that a clear distinction should be made between the materials "setting/settling", and the materials "drying out". The increasing moisture content levels exhibited in Figure 4 indicate a "wetting period" which appears to begin to even out towards the end of the fifth year. Years 6-10 were then identified as the period of stabilisation, when moisture levels reach equilibrium. It is proposed that this 10-year period should be simulated for both new build and existing buildings to portray a true reflection of what should be anticipated as in situ building performance. As a method to establish moisture dependent $U$-values from the data collated, the hygrothermal model data were extrapolated into $U$-value simulations for Year 10, as per Figure 5 and Table II.

The simulated $U$-value results display an increase in results year on year together with the increased moisture, stabilizing at the same time - Year 5/6, indicated using a 
IJBPA

38,1

62

Figure 4.

Moisture content graph of West wall simulation
Figure 5.

Simulated $U$-values for year 10 based on hygrothermal simulation
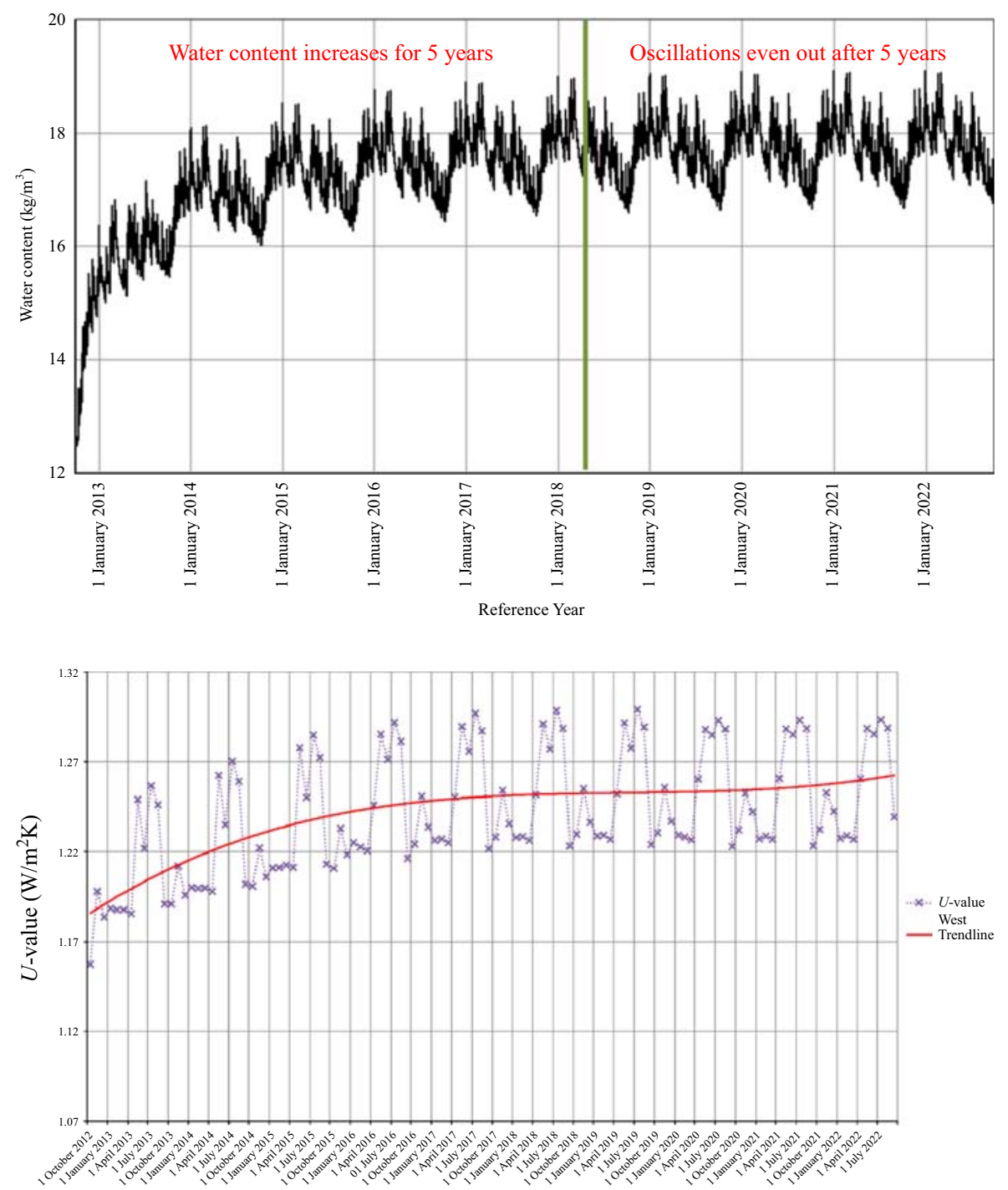

West $\left(\mathrm{W} / \mathrm{m}^{2} \mathrm{~K}\right)$

Table II.

Simulated $U$-values for case study

Avg.
Min.

1.256

1.227

Max.

1.294

polynomial trendline in red. Furthermore, the simulations suggest a seasonal shift in thermal performance, realizing the effect of the climate. This again suggests a strong link between moisture increase and $U$-value performance. Using the data provided though, the pattern of thermal performance suggests that the latter years of simulation should be 
extracted and applied as comparable figures against the in situ measurements, as they provide the representative figures of existing construction over 10 years old. Thus, the final year of simulation was averaged and plotted against the in situ measurements and the calculated $U$-value, as discussed and presented below.

In situ $U$-value data were administered by means of the progressive average procedure that is based on the idea that the average of instantaneous ratios between heat flux and temperature differences on a gradually increasing time scale levelling out the oscillations leading to the steady-state value of the $U$-value. In accordance with ISO 9869, the analysis was carried out over a period of 45 days, more than the 30 days suggested, as per Figure 6.

These results were then compared with the hygrothermal simulations in Figures 4 and 5 with corresponding environmental conditions and ISO 6946 standard method $U$-value calculations, assembled in Table III. The in situ measurements here displayed signs of
Thermal analysis

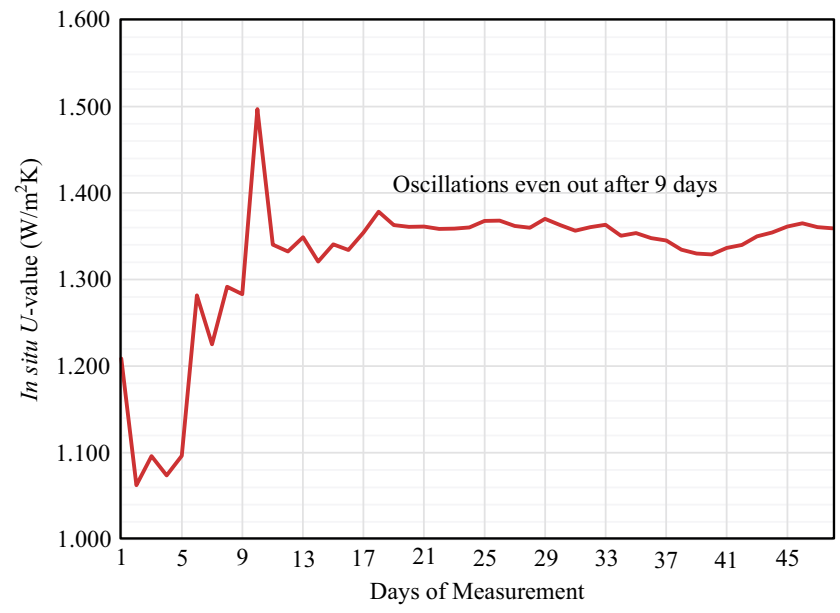

Figure 6.

Progressive $U$-value measurement of West façade

\begin{tabular}{cccc}
\hline Orientation & Calculated $\left(\mathrm{W} / \mathrm{m}^{2} \mathrm{~K}\right)$ & Simulated $\left(\mathrm{W} / \mathrm{m}^{2} \mathrm{~K}\right)$ & Measured $\left(\mathrm{W} / \mathrm{m}^{2} \mathrm{~K}\right)$ \\
\hline West & 1.083 & 1.255 & 1.359 \\
\hline
\end{tabular}
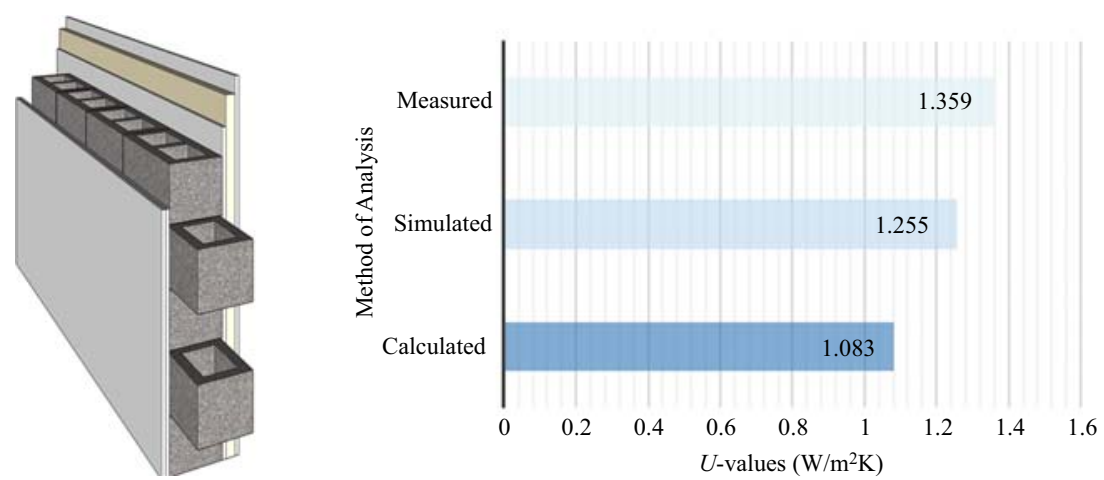

Table III.

Calculated, simulated and measured $U$-values 
IJBPA

38,1

fluctuation during the initial nine days, evening out after that to give a more accurate representation of the wall performance. This $U$-value was simulated as mentioned earlier, resulting in the data presented in Table III.

$U$-value measurements, as suggested in previous research by the author do not align with calculated $U$-values. Conversely, the simulated values align much closer with the in situ recorded data than these calculated $U$-values. The discrepancy between calculations and measurements appears to be bridged through simulation, something linked to orientation and age of the building, incorporating wind speed, relative humidity, solar transmittance and most critically rain/water content, as discussed in Chapter 5. Critically here though, the age of the fabric has been identified as a factor in the hygrothermal performance also.

\subsection{Discussion}

The findings of this research confirm that moisture has a significant impact on the thermal performance of an external wall, regardless of the overall assembly as previously suggested through hygrothermal simulation. Age dictates the level of moisture to be expected in the assembly as heavy mass wall constructions such as hollow block do not dry out, rather they wet. To accurately simulate a wall assembly, accurate data pertaining to the wall must be gathered including wall structure, cavity size (if any) and insulation type + thickness (internal, cavity or external). This information may have a profound effect on the thermal performance, thus designers and assessors designing/authenticating an external wall assembly should focus the design parameters around each façade considering the variation in associated external conditions. Hygrothermal performance appears to be a step in the right direction towards a progressive $U$-value prediction technique in Ireland. It is clear that the existing $U$-value calculation methodology is imbalanced with a number of flaws in its composition. This could be addressed using the knowledge derived from this research.

\section{Conclusions/further research}

This research has reviewed hygrothermal simulations in lieu of $i n$ situ $U$-value measurements and standard $U$-value calculations to advance results subsequent to previous experimental research. This research is intended to serve as an introduction to issues emanating from a larger research project to encourage researchers to understand and further explore the topic.

Reducing energy demand and CO2 through retrofitting of insulating and increasing standards for new builds, however without full understanding of the thermal performance created in doing so, the true resulting values and will not be realised.

With thermal refurbishment/retrofit holding a large percentage of potential to contribute towards energy reduction targets, it is hoped that government bodies and professional institutes will address these concerns and contribute towards the creation of a considered code of practice for thermal analysis and evaluation of existing and proposed dwellings. A key initial step is a general acceptance that current guidance on $U$-values is flawed and inadequate.

It is proposed that there is a need for training and education of existing and future industry professionals to understand and further explore the ideas presented here. A steep learning curve is anticipated with regard to understanding the contextual factors, the environmental variables and the identification of results and their impact.

Limitations do exist regarding availability of material values suitable for hygrothermal simulation. At present, there is no requirement for manufacturers or suppliers to provide these values and as such, they do not. It is anticipated that government bodies should address the fragility in current regulations and certification criteria to develop of a database of standard material values along with a prerequisite for material certification. This may tie 
in with existing material values developed and already contributed to The Department of Hygrothermics at Fraunhofer IBP for use in WUFI.

Another important conclusion of this study is that moisture levels within the external wall appears to increase steadily over five years from initial construction, while reaching a moisture equilibrium between 5 and 10 years from initial construction. An equally significant conclusion is that this moisture level at the moisture equilibrium is considerable. In contrast to current practice, this is a critical performance factor created through external climate conditions such as wind speed, rainfall and solar transmittance.

A more important affirmation made is that each orientation of wall performs differently due to climate, microclimate, exposure and construction materials within the wall build-up. This certainly requires more depth of research greater understanding, measurement and verification of the variables which can influence the resulting thermal performance.

\section{References}

Abdou, A. and Budaiwi, I. (2013), "The variation of thermal conductivity of fibrous insulation materials under different levels of moisture content", Construction and Building Materials, Vol. 43, June, pp. 533-544.

Ahn, K.-U., Kim, D.-W., Park, C.-S. and De Wilde, P. (2017), "Predictability of occupant presence and performance gap in building energy simulation", Applied Energy, Vol. 208, December, pp. 1639-1652.

Asdrubali, F., D'alessandro, F., Baldinelli, G. and Bianchi, F. (2014), "Evaluating in situ thermal transmittance of green buildings masonries - a case study", Case Studies in Construction Materials, Vol. 1, pp. 53-59.

Baker, P. (2008), "Preliminary results", in Scotland, H. (Ed.), In situ U-Value Measurements in Traditional Buildings, Historic Scotland.

Baker, P.H. (2011), "U-values and traditional buildings: in situ measurements and their comparisons to calculated values", Historic Scotland Technical Paper No. 10, Historic Scotland, Edinbirgh.

Board, T.G.C. (2013), “Closing the performance gap”, The Green Construction Board, available at: www. greenconstructionboard.org/images/stories/pdfs/performance-gap/2013-03-04\%20Interactive \% 20Image \%20ISSUE.pdf (accessed 25 June 2017).

Byrne, A., Byrne, G., Davies, A. and Robinson, A.J. (2013), "Transient and quasi-steady thermal behaviour of a building envelope due to retrofitted cavity wall and ceiling insulation", Energy and Buildings, Vol. 61, June, pp. 356-365.

Corbetta, P. (2003), Social Research: Theory, Methods and Techniques, Sage Publications.

Council, N.H.B. (2016), "Guide to your new home”, A Practical Guide to Looking After Your New Home, NHBC, Milton Keynes.

Creswell, J.W. (2009), Research Design: Qualitative, Quantitative, and Mixed Methods Approaches, Sage Publications.

Currie, J., Williamson, J.B. and Stinson, J. (2013), "Monitoring thermal upgrades to ten traditional properties”, in Scotland, H. (Ed.), Historic Scotland Technical Paper 19, Historic Scotland, Edinburgh.

De Mets, T., Tilmans, A. and Loncour, X. (2017), "Hygrothermal assessment of internal insulation systems of brick walls through numerical simulation and full-scale laboratory testing", Energy Procedia, Vol. 132, October, pp. 753-758.

Doran, S. (2000), "Field investigations of the thermal performance of construction elements as built", BRE (Ed.), DETR Framework Project Report, Glasgow.

Doran, S. and Carr, B. (2008), "Thermal transmittance of walls of dwellings before and after application of insulation”, BRE (Ed.), Energy Saving Trust, Glasgow.

Doran, S., Zapata, G., Tweed, C., Suffolk, C., Forman, T. and Gemmell, A. (2014), Solid Wall Heat Losses and the Potential for Energy Saving: Literature Review, BRE, Watford. 
IJBPA

38,1
Evangelisti, L., Guattari, C., Gori, P. and Vollaro, D.R. (2015), "In situ thermal transmittance measurements for investigating differences between wall models and actual building performance", Sustainability, Vol. 7 No. 8, pp. 10388-10398.

Flood, C., Scott, L. and Gleeson, W. (2016a), "In situ thermal transmittance of case studies in Dublin", Sustainable Ecological Engineering Design for Society (SEEDS), Leeds Beckett University.

Flood, C., Scott, L. and Gleeson, W. (2016b), “Application of transient hygrothermal modelling to assess thermal transmittance: a case study in Dublin, Ireland”, CIB World Building Congress 2016, Tampere.

Flood, C., Scott, L. and Gleeson, W. (2017), "Comparison of transient hygrothermal modelling against in situ measurement for thermal transmittance", in Dastbaz, M., Gorse, C. and Moncaster, A. (Eds), Building Information Modelling, Building Performance, Design and Smart Construction, Springer International Publishing, Cham, pp. 241-258.

Gomes, M.G., Flores-Colen, I., Manga, L.M., Soares, A. and De Brito, J. (2017), “The influence of moisture content on the thermal conductivity of external thermal mortars", Construction and Building Materials, Vol. 135, March, pp. 279-286.

Gorse, C. (2015), "Guest editorial: the sustainability challenge: measurement to reduce global emissions", Construction Innovation, Vol. 16, pp. 2-10.

Haralambopoulos, D.A. and Paparsenos, G.F. (1998), "Assessing the thermal insulation of old buildings - the need for in situ spot measurements of thermal resistance and planar infrared thermography", Energy Conversion and Management, Vol. 39 Nos 1-2, pp. 65-79.

Hulme, J. and Doran, S. (2015), "In-situ measurements of wall U-values in English housing”, BRE (Ed.), BRE, Watford.

Kampelis, N., Gobakis, K., Vagias, V., Kolokotsa, D., Standardi, L., Isidori, D., Cristalli, C., Montagnino, F.M., Paredes, F., Muratore, P., Venezia, L., Dracou, M.K., Montenon, A., Pyrgou, A., Karlessi, T. and Santamouris, M. (2017), "Evaluation of the performance gap in industrial, residential \& tertiary near-zero energy buildings", Energy and Buildings, Vol. 148, August, pp. 58-73.

Knapton, S. (2017), "Energy scandal: misleading efficiency claims leading to huge bills for homeowners", The Telegraph.

Künzel, H.M., Holm, A., Zirkelbach, D. and Karagiozis, A.N. (2005), "Simulation of indoor temperature and humidity conditions including hygrothermal interactions with the building envelope", Solar Energy, Vol. 78 No. 4, pp. 554-561.

Latif, E., Tucker, S., Ciupala, M.A., Wijeyesekera, D.C., Newport, D.J. and Pruteanu, M. (2016), "Quasi steady state and dynamic hygrothermal performance of fibrous Hemp and Stone Wool insulations: two innovative laboratory based investigations", Building and Environment, Vol. 95, January, pp. 391-404.

Litti, G., Audenaert, A. and Braet, J. (2013), "Energy retrofitting in architectural heritage, possible risks due to the missing of a specific legislative and methodological protocol”, The European Conference on Sustainability, Energy and the Environment, Brighton, pp. 1-9.

Little, J. (2009), "Breaking the Mould 1 - a study of condensation in single-leaf concrete wall upgrades", Construct Ireland, Vol. 4 No. 6.

Little, J. (2010), "Breaking the Mould 5: comparative simulation of internal insulation systems", Construct Ireland, Vol. 4 No. 12.

Marshall, A., Fitton, R., Swan, W., Farmer, D., Johnston, D., Benjaber, M. and Ji, Y. (2017), "Domestic building fabric performance: closing the gap between the in situ measured and modelled performance", Energy and Buildings, Vol. 150, September, pp. 307-317.

Maxwell, J.A. (2013), Qualitative Research Design: An Interactive Approach: An Interactive Approach, Sage Publications.

Peng, C. and $\mathrm{Wu}, \mathrm{Z}$. (2008), "In situ measuring and evaluating the thermal resistance of building construction", Energy and Buildings, Vol. 40 No. 11, pp. 2076-2082. 
Rhee-Duverne, S. and Baker, P. (2013), "Research into the thermal performance of traditional brick walls”, Heritage, E. (Ed.) London.

Rye, D.C. (2010), "U-value report", The SPAB Research Report 1, SPAB, London.

Thermal analysis

Rye, D.C. and Scott, C. (2012), "U-value report revised”, The SPAB Research Report 1, SPAB, London.

SEAI (2015), "Unlocking the energy efficiency opportunity: summary for policymakers", SEAI, Dublin.

Zirkelbach, D., Mehra, S.R., Sedlbauer, K.P., Künzel, H.M. and Stöckl, B. (2017), “A hygrothermal green roof model to simulate moisture and energy performance of building components", Energy and Buildings, Vol. 145, June, pp. 779-791.

\section{Corresponding author}

Cormac Flood can be contacted at: cormac.flood1@gmail.com

For instructions on how to order reprints of this article, please visit our website: 